\title{
Innovations
}

\section{Establishing psychiatric attachments to general practice: a six stage plan}

\author{
Geraldine Strathdee, Consultant Psychiatrist, The Maudsley Hospital, Denmark \\ Hill, London SE5 8AZ; Nigel FisHeR, Senior Registrar, The Maudsley Hospital; and \\ Elizabeth McDonald, Research Psychiatrist, Institute of Psychiatry, DeCrespigny \\ Park, Denmark Hill, London SE5 8AF
}

Since the 1970s there has been a growing trend for psychiatrists to establish formal attachments to primary care and these now form an important component of community psychiatry (Strathdee \& Williams, 1984). In this paper a six stage plan for the establishment of a psychiatric attachment is proposed. The framework outlined may be modified in the light of local service, training and research needs.

\section{Stage 1: establishing a rationale and objectives}

"What role will the primary care clinic serve within the existing or developing psychiatric service?'"

The development of psychiatric attachments to primary care has been initiated by "grass-roots" clinicians and has occurred in the context of changes in the organisation of psychiatric and primary care services (Strathdee \& Williams, 1984). Firstly, the growth of primary care attachments found part of the growing community care movement. Secondly, the siting of the clinics within primary care facilities has been seen as a way of countering the dissatisfaction with outcome and communication in hospital out-patient clinics. Thirdly, the move to large multipractice health centres literally provided room for visiting psychiatrists. Stated objectives of liaison with primary care have included improved patient attendance at clinics and mutual education of the psychiatrist and primary care team. In addition liaison has been shown to be helpful in attracting at risk groups such as the homeless.

\section{Stage 2: identifying a practice}

"In which practices can need and feasibility be accommodated?"

Suitable practices include those in the areas of greatest psychiatric morbidity and heavy referrers to psychiatric services. Equally important is the charac- ter and nature of the individual practice. Most clinics have been established in large health centres. Such centres have the physical resources to accommodate the psychiatrist, are likely to generate a critical mass of referrals and are already geared to teamwork. More controversially, they may be seen as more forward looking and open to innovation. However, small or single handed practices should not be ignored (Brown \& Tower, 1990).

The attachment should be developed as a joint venture between psychiatrist and general practitioner. In initiating an attachment an exploratory letter is sent to the senior partner of local practices and then followed up with a phone call to allow further discussion. If there is interest, a meeting, preferably with all the partners, should be arranged to discuss the format and practicalities.

\section{Stage 3: negotiating the practical aspects "When, where and how of ten?"}

The frequency and timing of sessions, the room to be used and the length of time allocated to see patients needs to be negotiated from the outset in consultation with the practice manager and receptionist as well as the GPs. To facilitate joint working it is essential that sessions occur at the same time as the GPs hold their surgeries, and when all partners are present. The frequency of sessions will depend on the amount of work generated, typically one session weekly or monthly is adequate. Receptionists are used to booking in GPs' patients every 6-8 minutes and a separate diary which indicates clearly the longer times for psychiatric consultations should be used.

\section{Stage 4: selecting a model \\ "Which model of interaction is best suited to the working practices of the psychiatrist and GPs?"}

A number of models of primary care attachment have been described which involve varying degrees 
of interaction between referring GP and attached specialist (Mitchell, 1985). These include informal "lunchtime meetings" and the more formal "consultation" style where GPs present cases to the psychiatrist, who advises on diagnosis and management, but does not see the patient. The most commonly implemented is the "shifted out-patient" model which frequently evolves to the "joint assessment" model. In this the GP and psychiatrist undertake a combined assessment with the patient; management is undertaken by the GP, with continuing advice from the specialist. The most sophisticated model is the "liaison-attachment team" where long-term contact between primary care and mental health teams results in a transfer of skills and responsibilities.

The choice of format depends on the degree of GP involvement in assessment and continuing treatment of referred patients. Overall superiority has not been demonstrated for any one model. To determine the format that best suits the individual circumstances and personalities involved, it is useful to experience each other's working practices, for example by sitting in on a GP surgery. While GPs may be reluctant to undertake joint assessments because of the length of time involved, it is worth reiterating that each partner makes only 2-10 referrals a year. A closer style of working together may need to evolve over time and the choice of model may need to be altered as the attachment develops.

\section{Stage 5: referring patients \\ "Which patients will be seen?"}

It is essential to clarify and agree on which patients are most likely to benefit from referral to the psychiatrist. The psychiatric morbidity seen by general practitioners is primarily adjustment reactions, neuroses and personality disorders. However, psychiatrists working in primary care tend to be referred those with severe mental illness. The psychiatrist on site is well placed to redirect appropriate referrals to non-statutory and community based agencies.

The development of a standardised written referral and assessment form helps ensure that appropriate information is available for both psychiatrist and GP and provides ready data for audit and review. The GP should detail: present medication; past psychiatric history; description of present symptomatology; and duration of the present problem. The reverse should be left free for the psychiatrist to record the outcome of the assessment and details of treatment including: diagnosis; indication of suicide risk; prognosis; follow-up; and treatment advised (Williams \& Wallace, 1974). The written referral should be followed up with a face to face discussion with the referrer before the assessment. This provides an opportunity to focus on those aspects of a case not easily communicated in writing, for example concern about the doctor-patient relationship.

\section{Stage 6: managing the patient \\ "Who does what?"}

Whatever model of working is adopted, opportunities for developing joint working practices should be maximised. In our experience, two of the most successful strategies include discussion of the referral before and after assessment, and prescribing responsibility remaining with the referring GP. The development of pre-assessment work such as diaries or life charts, coordinated by the referrer, improves patient care and increases the GP's understanding of psychiatric disorder and associated treatments. The training aspect is cited by GPs as one of the main advantages of primary care liaison schemes, and its importance should not be overlooked.

Finally, there is the key issue of clinical responsibility. Again the best strategy is for a clear agreement to be made at the beginning of any attachment. Our opinion is that, except in exceptional circumstances, responsibility should remain with the general practitioner.

\section{Secrets of success}

We have attempted to describe a logical approach to establishing a psychiatric attachment to general practice. However, a successful attachment may prove elusive, depending as it does on a range of variables that are the consequence of the individual vagaries of practitioners and practice. In particular, the relationship between hospital specialist and general practitioner was traditionally a hierarchial one, and its renegotiation is part of the process of developing a good working alliance (Horder, 1989). Joint projects such as developing inventories of local resources or collaborative research help foster good relationships.

It is worthwhile paying attention to the more informal aspects of practice life. The visiting psychiatrist should welcome any invitation to take part in practice meetings and coffee breaks as they provide an invaluable opportunity to develop an understanding of the remit of general practitioners. Soliciting the assistance of non-medical staff is vital; failure to involve receptionists has resulted in sessions being conducted from a broom cupboard with patients being booked in every 6-8 minutes!

\section{Conclusion}

The organisational strategy described is an attempt by us to facilitate the planning of psychiatric attachments to primary care. This is an exciting and 
developing field and we would be interested to learn of other approaches which have contributed to the success of such attachments.

\section{References}

Brown, L. \& Tower, J. (1990) Psychiatrists in primary care: would general practitioners welcome them? Journal of the Royal College of General Practitioners, 40, 369-371. HORDER, J. (1988) Working with general practitioners. The British Journal of Psychiatry 153, 513-521.
Mrtchell, A. (1985) Psychiatrists in primary health care settings. British Journal of Psychiatry, 147, 371-379.

StrathdeE, G. \& Williams, P. (1984) A survey of psychiatrists in primary care: the silent growth of a new service. Journal of the Royal College of General Practitioners, 34, 615-618.

Williams, P. \& WALlACE, B. (1974) General practitioners and psychiatrists do they communicate? British Medical Journal, $i$, 505-507.

A full list of references is available from Dr Strathdee.

\title{
A mothers' group in a child guidance clinic
}

\author{
AnNeTte Goulden, Senior Registrar; and Elund Dorkings, Registrar, The Park \\ Hospital for Children, Headington, Oxford OX3 7LQ
}

We decided to set up a short-term, closed group of mothers attending our local clinic, with the following questions in mind.

Is group therapy helpful for parents of children referred to child guidance clinics? Will they benefit from the therapeutic factors associated with group work: instillation of hope, universality, catharsis, interpersonal learning and group cohesiveness? (Vinogradov \& Yalom, 1989).

Can change be achieved by brief intervention? Research by Benson \& Turk (1989) implied that time limited groups are viable. They ran a 20 month group for anxious and depressed mothers, and sited a positive outcome as a fall in consultation rates, possibly due to a reduction of externalisation of maternal problems onto their children.

How would change be assessed in our group? We predicted that mothers would construe problems differently and that children would change in response to their mothers' altered perceptions and behaviour.

What would mothers wish to discuss? Ruel \& Adams (1981), described 12 themes which became apparent over six months. Would similar themes evolve in our short-term group?

\section{The study}

\section{Group setting}

We selected mothers from the previous 12 months clinics and told each that the group would meet for ten one hour sessions to discuss parenting issues. Members would gain by sharing their problems and by helping others from their own experience, within the context of confidentiality, punctuality and commitment.

\section{Group members}

The nine mothers were aged between 28 and 46 years. One was receiving treatment for depression, another had a history of alcoholism, and a third of drug abuse. Two worked from home and seven were fulltime housewives. Their children ranged in age from 12 to 17 years. Two attended public schools, four went to state schools and three were at college. One had Asperger's syndrome, two were depressed, three had conduct disorder and one child refused to go to school. One child had psychosomatic "fits" and one teenager had agoraphobia.

\section{Structure of the sessions}

At the beginning of each session, we facilitated expression of feelings around the roles of daughter, mother, lover and wife. Towards the end we highlighted a major theme which delivered a clear message for the participants to take home.

\section{Outcome}

\section{Group development}

In the first three sessions members became mutually supportive as they realised that they were not different in their problems as mothers. Discussion concentrated on management of their children's problems.

By the fourth session, the group had stabilised, members sat in the same place each week. They expressed anger towards their husbands and children and towards those seen to be incompetent and uncaring: teachers, psychologists and doctors. This was interpreted as covert anger towards us as imperfect "parental" therapists. 